\title{
Study on Strategies of Energy Saving and Emission Reducing Building Design in Urban and Rural Areas
}

\author{
Hongyan Li, Jia Yu \\ Department of Architecture, Faculty of Human Settlement and Civil Engineering, Xi'an Jiao-Tong University, Xi'an, Shaanxi, China
}

\section{Email address:}

lihy04@126.com (Hongyan Li), 1152715229@qq.com (Jia Yu)

\section{To cite this article:}

Hongyan Li, Jia Yu. Study on Strategies of Energy Saving and Emission Reducing Building Design in Urban and Rural Areas. American Journal of Civil Engineering. Vol. 4, No. 3, 2016, pp. 98-103. doi: 10.11648/j.ajce.20160403.16

Received: March 10, 2016; Accepted: April 15, 2016; Published: May 24, 2016

\begin{abstract}
In China, huge building energy consumption is the most prominent problem in the current situation of energy consumption. It has caused a series of energy and environmental problems. Therefore, it is extremely urgent and significant to study energy saving and emission reducing strategies in the aspects of building orientation, separation distance, solar radiation, wind direction, internal and external environment, etc. This paper discusses current situation and development trends of building design on energy saving and emission reduction in urban and rural areas of China. Through discovering existing problems in building energy consumption and architectural design in China, this paper proposes strategies of energy saving and emission reduction in architectural design and analyzes specific measures in architectural design through the typical case study.
\end{abstract}

Keywords: Energy Saving, Emission Reduction, Building Design Strategies

\section{Introduction}

In China, construction, industry and transportation form three major energy consumption fields. With the rapid development of urban construction, the traditional energy has been increasingly exhausted. As a big country in the field of architecture, a large amount of building energy consumption also become a huge burden on the national economy in China. In addition, the environmental pollution caused by energy crisis and climate change is increasingly serious. Under this background, the energy-saving and emission reduction buildings have become a popular trend in today's society. Thus, in order to have a harmonious future, it's critical to absorb the successful experiences from developed countries and promote the energy-saving and emission-reduction by means of architectural design. In this way, will China can realize the dream of energy conservation, environmental improvement and social sustainable development.

\section{Current Situation and Development Potential of Energy Saving and Emission Reduction in Urban and Rural Buildings}

\subsection{Background of Building Energy Saving and Emission Reduction}

In China, building energy consumption accounts for more than $27 \%$ of the total energy consumption and is increasing at an annual rate of 1 percentage points [1]. This phenomenon presents a trend of low level energy consumption, serious waste, and high potential energy consumption. Relevant statistics show that China's construction steel consumption accounted for about $25 \%$ of its total amount, cement usage accounted for $70 \%$ of the total amount of national cement, wood consumption accounted for $40 \%$ of the national total amount, the construction of water consumption accounted for $32 \%$ of the total. This has exacerbated the pressure to the environment [2].

Not only does the building have a high consumption of energy, but the energy utilization rate is also extremely low. Construction Department statistics show that China's 
urban and rural construction area of new housing construction is nearly 2 billion square meters per year, of which more than $80 \%$ are high energy consumption buildings. More than $95 \%$ of existing buildings are high energy consumption [3]. China's building energy efficiency is still relatively backward, so building energy efficiency technology has to be improved.

According to the experience from developed countries, energy consumption of building construction will exceed that of industry, transportation and other industries, and ultimately be in the first place of social energy consumption, so the study of energy-saving and emission reduction is imminent. Firstly, China has the world's largest construction market, so only by adhering to the energy saving development, clean development and security development, can we achieve reasonable and fast economic development. Moreover, building is one of the main sources of greenhouse gas emissions, which has a significant impact on climate change. The carbon dioxide gas emission from construction industry accounts for about $30 \%$ of the total emissions of greenhouse gases. Therefore, low-carbon housing is not only conducive to energy-saving and emission reduction, but also significant to deal with global climate change. Most importantly, reasonable building design considering energy-saving can benefit the construction of a resource-saving and environment-friendly society and a sustainable environment.

\subsection{Problems of Urban and Rural Building Design Regarding Energy Saving and Emission Reduction}

The problems and challenges can be generalized into five aspects.

\subsubsection{Unreasonable Construction Layout}

Some residential plans do not consider natural ventilation and residents often use air condition to adjust the indoor temperature and humidity, which increased the energy consumption.

\subsubsection{Massive Use of Glass Curtain Wall Causes Large Energy Consumption}

In many cities, the pursuit to beautiful and stylish building has lead to many office buildings with glass curtain wall. It causes light pollution in summer for strong ultraviolet radiation and no heat preservation in winter. People have to use high-power air conditioner to adjust the temperature throughout a year. The glass curtain wall brings about the so-called aesthetic feeling, but also causes the energy consumption doubled. For example, the Shanghai Pudong cadre's college main building is like a big glass columns without heat insulation (Figure 1). And its annually electricity fee is 2 3 times higher than other general buildings.

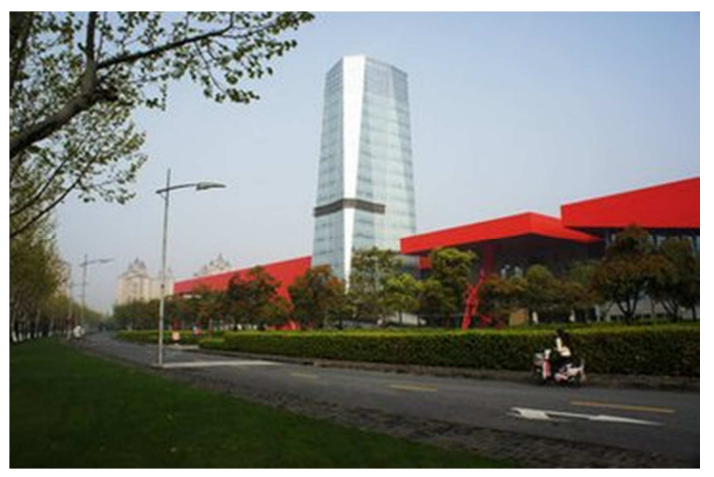

Figure 1. Shanghai Pudong cadre's college main building.

\subsubsection{High Energy Consumption of Reinforced Concrete Structure}

Relevant study shows that the energy consumption and carbon dioxide emissions from timber building structure are the least, followed by the light steel structure [4]. The energy consumption of concrete structure is the most in the three kinds of structures. The massive use of reinforced concrete structure has led to a greater increase in the construction energy consumption and caused more pollutant emissions.

\subsubsection{Serious Thermal Phenomenon}

In the architectural design, the building envelope plays an important role in the building insulation. It is the key to building energy efficiency. The kaleidoscopic designs easily cause the heat transfer coefficient of a part in construction far greater than in the adjacent parts. The thermal resistance becomes smaller and the thermal insulation performance of the building envelope is worse. Or the heat dissipation area of a part of the building is larger than the heating area, causing heat loss too much, which leads to the phenomenon of thermal bridge, resulting in a waste of energy.

\subsubsection{Insufficient Utilization of Clean Energy}

In the past, relying on combustion of traditional energy has caused a waste of energy and increased the environmental pollution. So it is imperative to use clean and convenient energy. For example, the use of solar energy is has a large room for improvement.

\subsection{Development Potential of Energy Saving and Emission Reduction in China}

There are three main reasons for high building energy consumption: poor heat insulation of building envelope, low heating system efficiency and low heat source efficiency. In the about 40 billion square meters existing buildings, there are widespread problems such as poor building envelope insulation and low heating air-conditioning system efficiency [5]. The energy saving potential is huge.

In addition, the energy saving potential of public building is also great. The energy consumption level of large public buildings is several times of ordinary buildings and the overall energy use efficiency is far lower than that of the developed countries. The energy saving potential of existing public building is large and energy saving can be 
approximately $30 \%$ (Figure 2 ). In addition, the proportion of new buildings using advanced technology to achieve energy saving exploration in 2012 of China is only about $26 \%$, far lower than it in the United States and Japan [6].

\section{Power consumption of office building}



In fact, Chinese ancient buildings have taken the natural ventilation design into account, such as Huizhou style architecture (Figure 4) or Lingnan architecture, which has a small courtyard surrounded by attic and forms a natural ventilation corridor. In this way, building itself becomes a ventilation chimney, which makes natural ventilating effect much more obvious.

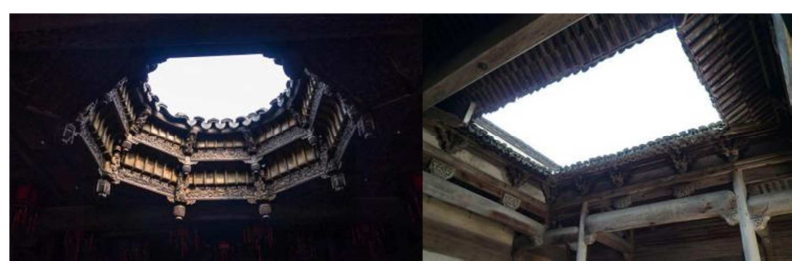

Figure 4. Courtyard styles in Huizhou architecture.

Secondly, the orientation of building should depend on the location and relationship with the surrounding environment and roads. In most situations, Chinese construction is suitable to choose the south-north orientation or close to the south-north orientation because cooling load in this direction is smaller than the east-west orientation and the index of energy consumption can also be reduced by about $5 \%$.

In addition, the shape coefficient is an important indicator of the thermal characteristics of building, which is related to the number of layers, size, shape and other factors. The larger the shape coefficient, the larger is the external envelope of building. When building volume is a certain value, the larger the outer protecting structure area, the bigger is the heat loss, and when the shape coefficient increases 0.01 , the energy consumption indicator will increase about $2.5 \%$ [2]. However, in order to solve the sunshine requirements of many high-rise buildings, sometimes architects make concave or convex changes in the flat and elevation, which leads to buildings' shape coefficient not conducive to the building energy efficiency. Therefore, the shape coefficient should be considered in the construction design, and it is not encouraged to pursue a better shape at the cost of the building energy consumption.

\subsection{Building Envelope Design}

The energy consumption caused by building envelope dissipation, heating and cooling system accounts for the majority in the whole building energy consumption, so more attention should be paid to the building envelope insulation (Figure 5). To strengthen the roof and exterior wall heat preservation and heat insulation performance, it is necessary to design a reasonable external insulation system and to use energy-saving insulation materials and construction technology, which can help in an effective way to improve the insulation performance of the wall and also can solve the common phenomenon of cracking and water seepage meanwhile. In addition, light color surface material can be used to reflect sunlight and enhance the external wall and roof insulation in summer from a certain extent. Furthermore, outside window is also a critical part of the building envelope. In general, the area ratio of building walls and windows in

Figure 3. Effect of architectural design on ventilation. 
the north is no more than $25 \%$, south is no more than $35 \%$, east and west is no more than $30 \%$ [8]. In this way, it can not only meet the requirements of indoor lighting and ventilation, but also reduce the energy consumption that is due to the poor heat preservation and heat insulation.

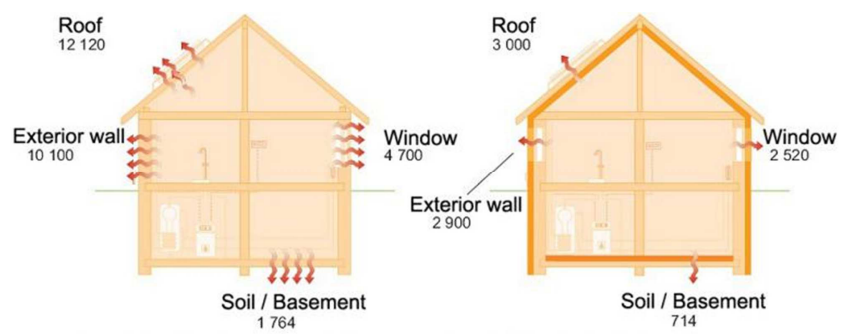

Figure 5. Comparation of heat dissipation with building envelope insulation (Left) and without building envelope insulation (Right).

\subsection{Use New Type of Energy Saving and Environmental Friendly Building Materials}

In China, many new energy-saving and environmental protection building materials have been developed from blankness, variety from single to diversity and quality from low to high, especially the new wall materials develop faster and more varieties, such as hollow clay brick (Figure 6), clay brick mixed with waste, composite panels, etc. For example, energy-saving brick used in rural houses has the advantages of saving energy and soil compared with clay brick, and it is also the superior new building materials. Moreover, comparing to cement, the use of ecological cement and coal ash are the powerful measure for energy saving and emission reduction (Figure 7). Ecological cement is a kind of ecological building materials made from various kinds of industrial wastes and coal ash is the waste of coal-fired power plant. Since coal ash has the characteristics of light, porous and potential water hardness, it can be a raw material of various building materials. The use of this kind of cement and coal ash can reduce the load of waste disposal, which not only solves the pollution caused by waste, but also makes living garbage and industrial waste become raw materials into useful construction resources, thereby reducing the cost of production.

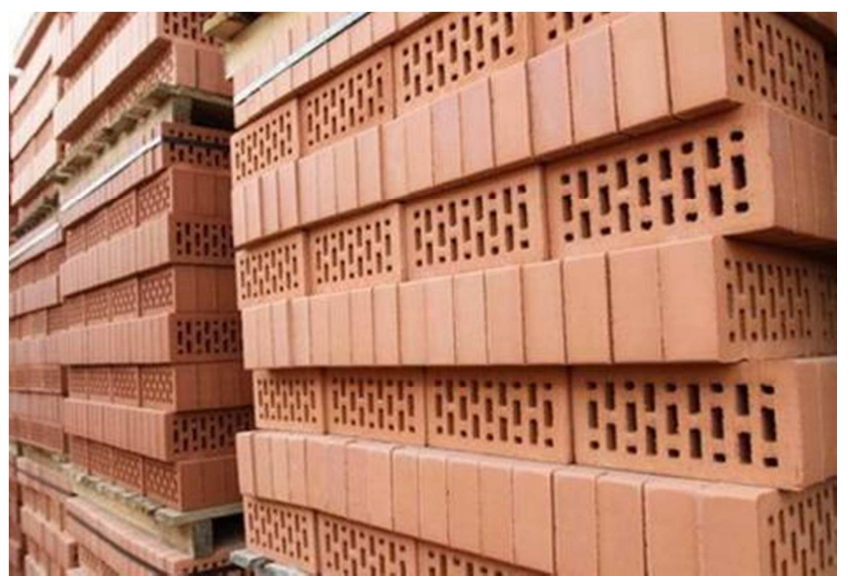

Figure 6. Hollow clay brick.

\section{Ecological cement}

$8 \% 1 \%$



Ordinary Portland cement

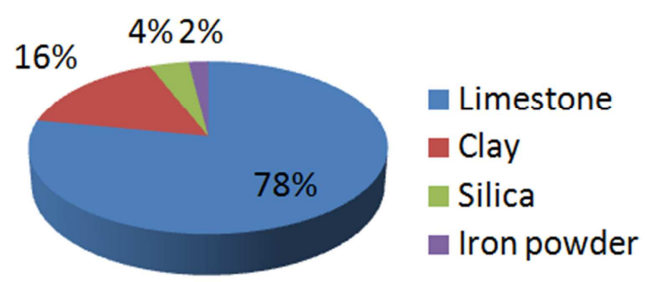

Figure 7. Comparation of components of common cement and ecological cement.

\subsection{Architectural Shading Design}

Too much sunshine into the interior can cause indoor too hot and increase the energy consumption of air-conditioning. So it is necessary to take certain shading measures in some rooms or outdoor to ensure the indoor comfortable environment. However, contribution of different shading technology to energy saving is not the same. The visible light and energy transmittance of ordinary transparent glass is almost $100 \%$. About $75 \%$ of the light and heat will enter the room if internal shading is set, such as setting control blinds or curtains. But if the outer sunshade is installed, sunshine thermal effect will reduce more than $80 \%$ (Figure 8) [9]. In addition, it is necessary to promote a variety of measures such as roof shading, external wall shading, planting trees to reduce solar radiation.

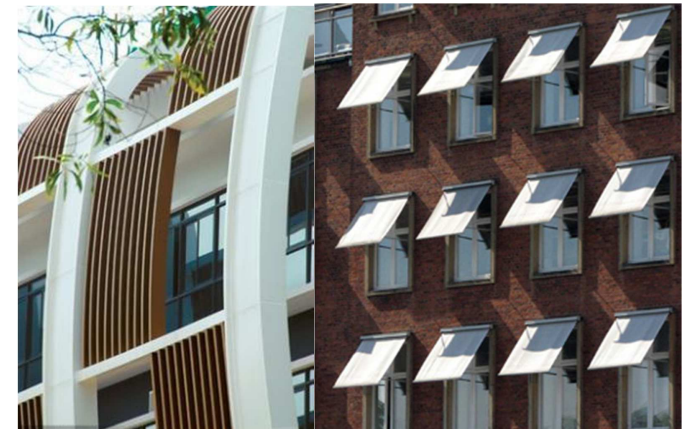

Figure 8. Examples of shading measures.

\subsection{Promotion of Three-Dimensional Afforesting}

Building three-dimensional green space is a very efficient and cheap energy-saving method. Greening or planting crops in roof, facade and public building surface can save $30 \%$ energy of the air-conditioning in summer [10], which could not only create a comfortable indoor environment and significantly reduce urban heat island effect and dust emissions, but also beautify the environment (Figure 9). 

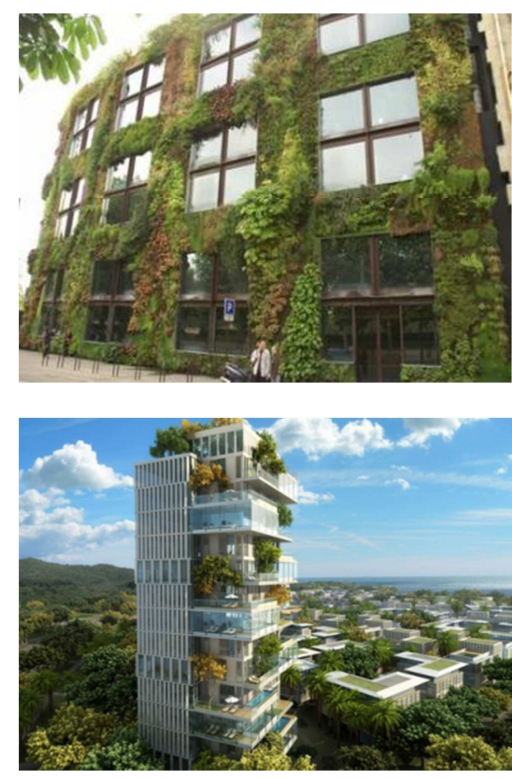

Figure 9. Three-dimension afforesting.

\section{The Case: Headquarters Building of Frankfurt Commercial Bank (Germany)}

Commerzbank headquarters was built in 1997 completed by $\mathrm{N}$ Forster in 1994. This triangular tower is 53 stories and 298.74 meters high, which is not only the world's first high-rise ecological architecture, but also the world's highest ecological architecture (Figure 10). Except for a very small part of cold or hot weather, the whole building uses natural daylight, natural ventilation and temperature adjustment, reduces energy consumption to a minimum degree.

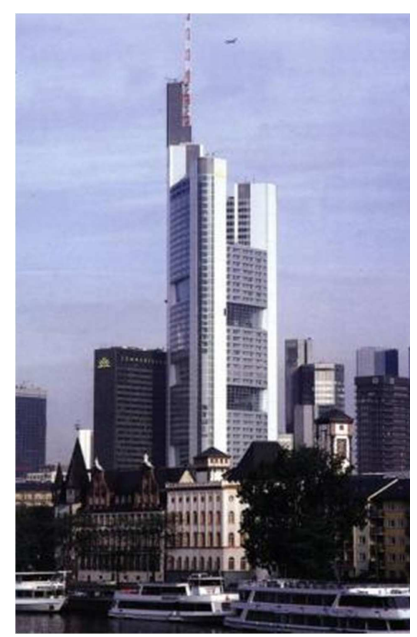

Figure 10. Overall effect diagram of Commerzbank headquarters.

\subsection{Layout Analysis}

The building plane is an equilateral triangle shape with 60 meters in each side (Figure 11). Forster reconfigured the internal and external environment of the traditional office towers. He made indoor and outdoor mutual fusion by introduced outdoor environment inside. He dispersed public transportation and other core (elevator, step ladder, toilet, etc.) in the center of the tower to the three corners of the triangle layout of the construction, and treated the structure's triangular vertex of the three independent frame tube as giant column and the eight story steel frame as the giant beam, which connected and formed the giant tube system. Thereby, it liberates the larger space in center to redesign. Trapezoidal sections between each of the two parts of the traffic are the main office building. The three trapezoidal formed a hollow triangular atrium. Forster arranged sky gardens up to 4 layers (about 14 meters) at these trapezoidal areas between every 8 layers. The gardens are scattered set and enable people in each layer office can enjoy the garden landscape.

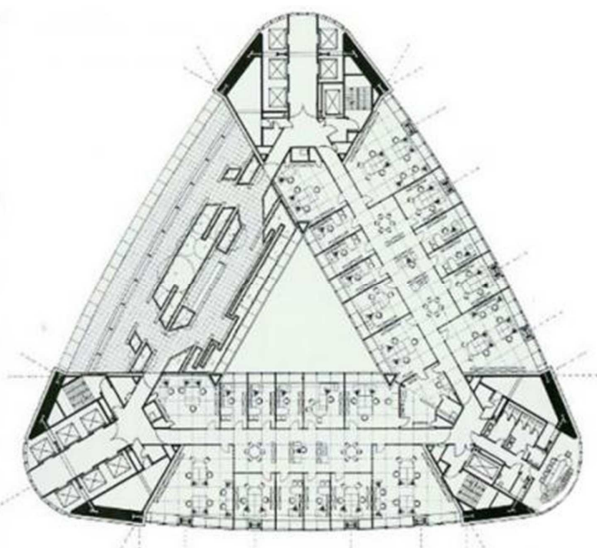

Figure 11. Plan layout diagram of Commerzbank headquarters.

\subsection{Facade Analysis}

In addition to the design of atrium and interior garden, the double deck design approach on construction also adds to the high-rise building some green space (Figure 12). The outer layer is fixed by a single layer of glass, and the inner layer is adjustable double Low-E insulating glass. The two layers form a hollow part of $165 \mathrm{~mm}$ thick between them, which can allow the outdoor fresh air and the indoor stale air to exchange when the inner window is open. In the hollow part, window-shades which can be used to adjusted indoor environment are also set up. It can block the direct sunlight in hot summer and can reflect more sunlight into the interior in cold winter.

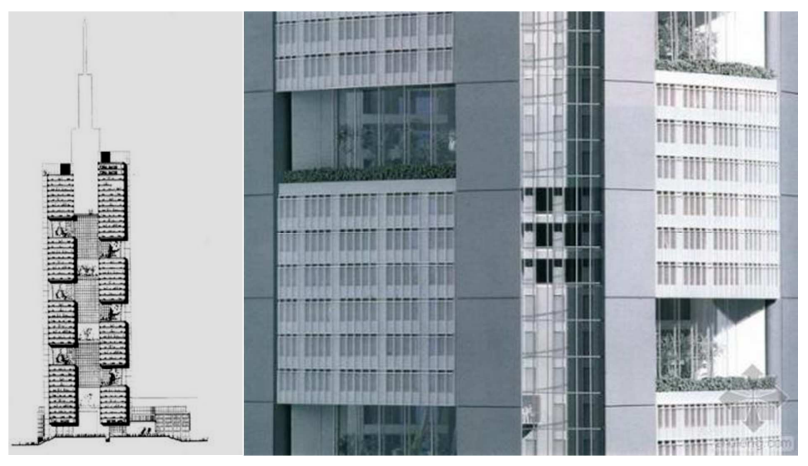

Figure 12. Facade of Commerzbank headquarters. 


\subsection{Daylight and Air Flow Analysis}

The triangular atrium formed in the building is like a large chimney, which is organized by the natural ventilation of the office space in order to exert its chimney effect. After the wind tunnel test, a number of air gardens were set up in the three office space. And they are distributed in three directions of different elevation, as the air inlet and outlet of the "chimney", which organized the natural ventilation in office space effectively.

Triangular layout can maximize the acceptance of sunshine, create ideal vision, and reduce the blocking to adjacent building at the same time. Unique open top lighting design also makes the building have plenty of sunshine. The atrium and the air garden make the building meet the needs of internal ventilation and lighting only through natural ventilation and natural lighting at most of the work time throughout a year.

\subsection{Landscape Analysis}

This kind of closing to nature design creates a natural plant community in the primness building and overcomes the primness and depression of the former office. This Atrium space is a lively green environment full of sunshine, which can effectively regulate people's mental state and play a positive role in alleviating fatigue. This green office building gives people not only the visual comfort, but also space and nice mood to pursue health.

The comprehensive application of all these above-natural lighting, ventilation method and intelligent control technology makes the rate of the building natural ventilation reach $60 \%$, which is rare in high-rise buildings.

\section{Conclusions}

Building energy saving and emission reduction is a highly technical and very complex process. These two aspects have both connections and differences. Generally, energy saving will lead to emission reduction, while emission reduction is not necessary energy saving. Thus the emission reduction projects must strengthen the application of energy-saving technology to avoid the result of one-sided pursuit of the energy consumption and focus on the balance of social benefits and environmental benefits. Although the initial investment of many design of energy-saving and emission reduction is large, technology is difficult and efficiency is low, energy-saving and emission reduction are the direction of new building design. This will benefit sustainable development of urban and rural areas. This is a long-term benefit, so the exploration of energy-saving and emission reduction building design should be continued. At the same time, we should combine the construction function with art and technology, and strive to control energy growth and protect environment with the continuous growth of total construction in order to reduce the running cost of buildings and to develop on the road of intensive, intelligent, green and low carbon. It is significant to achieve self-sufficiency in terms of building energy and to construct "zero energy building" to realize ecological sustainable development of building industry.

\section{Acknowledgements}

This work was financially supported by the National Natural Science Foundation of China (51308451).

\section{References}

[1] Wenjuan Tang: The Current Situation of Building Energy Consumption in China. Urban and Rural, vol. 25 (2010), pp. 47-49, in Chinese

[2] Linde Liu: The Present Situation of Building Energy Consumption, Energy Saving and Emission Reduction Design and Renewable Energy Utilizationin in China. Hydropower Station Design, vol. 25 (2009), pp. 107-118, in Chinese

[3] Yang Y H: Green Building Development Features in China. Applied Mechanics \& Materials, vol. 9 (2014), pp. 725-730, in English

[4] Chunjing Shang, Chenglong Chu, Zhihui Zhang: Comparison of Carbon Emissions in Different Structural Buildings' Life Cycle. Building Science, vol. 27 (2011), pp. 66-70, in Chinese

[5] Guang Yang: Thinking of Building Energy Consumption. Care for Tomorrow, vol. 1 (2015), pp. 18-19, in Chinese

[6] Pengju Yuan: Exploration of Energy Saving Measures in Architectural Design. Construction Engineering Technology and Design, vol. 27 (2015), pp. 13-16, in Chinese

[7] Baoxing Qiu: Six Major Fields of Building Energy Saving and Emission Reduction and Its Prospect. Heating and Cooling, vol. 10 (2011), pp. 26-28, in Chinese

[8] Shasha Wei, Huijiao Wei, Chunling Wu: Study on the Influence of Different Side Window Lighting Methods on the Lighting Energy Saving in Green Office Buildings. Refrigeration and Air Conditioning: Sichuan, vol. 4 (2015), pp. 368-373, in Chinese

[9] Yun Ding: Discussion on External Shading Application of Buildings in the Hot-Summer and Cold-Winter Zone. Huazhong Architecture, vol. 1 (2016), pp. 70-73, in Chinese

[10] Aijuan Chen, Yuhui Di: Research Status and Development Trend of Roof Greening. Clean and Air Conditioning Technology, vol. 2 (2013), pp. 46-49, in Chinese 